Article

\title{
Does Environmental Regulation Affect Natural Gas Consumption? Evidence from China with Spatial Insights
}

\author{
Xiaolin Wang ${ }^{1}$, Xiangyi Lu ${ }^{1, *}$, Na Zhou ${ }^{1}{ }^{\circledR}$, Jianzhong Xiao ${ }^{1}\left(\mathbb{D}\right.$ and Jun Chen ${ }^{2, *}$ \\ 1 School of Economics and Management, China University of Geosciences, Wuhan 430074, China; \\ wangxiaolin_cug@163.com (X.W.); nazhou@cug.edu.cn (N.Z.); xjianzhong@cug.edu.cn (J.X.) \\ 2 School of Marxism, China University of Geosciences, Wuhan 430074, China \\ * Correspondence: 1xy_cug@163.com (X.L.); cj_cug_2010@163.com (J.C.); Tel.: +86-18632387003
}

Received: 11 March 2020; Accepted: 15 April 2020; Published: 20 April 2020

check for updates

\begin{abstract}
How environmental regulations affect natural gas consumption in China is an urgent issue that must be addressed to achieve the optimal allocation of natural gas resources. The nonspatial panel model and spatial Durbin model have been applied in this paper to explore the impact of environmental regulation on gas consumption and the influence mechanism of such regulation. The results show that there is a $\mathrm{N}$-inverted curve between environmental regulation and gas consumption at the national level. Three main mechanisms (or paths) by which environmental regulation affects natural gas consumption are discovered: controlling the total amount of coal in the energy mix, reducing industrial coal consumption and adjusting energy market prices. The first and third paths positively and significantly affect gas consumption, while the second path negatively affects gas consumption. Second, the spillover effects of environmental regulation promote the growth of gas consumption and integration of the natural gas market at the national level. Considering the provincial level, however, some regions have high regulation-high gas consumption intensity $(\mathrm{HH})$, while others have low regulation-low gas consumption intensity (LL). Based on the above conclusions, we give recommendations for improving energy regulations in different regions to promote the development of regional natural gas markets.
\end{abstract}

Keywords: natural gas consumption; environmental regulation; government competition; influence mechanism

\section{Introduction}

Environmental regulation, as a powerful tool for ecological and environmental management, is committed to the coordination of environmental protection and economic growth. Environmental regulation, under the guidance of the sustainable development goals, has two different impacts on the energy consumption structure [1]: First, environmental regulation induces economic activities to evolve toward green, low-carbon development by decreasing dependence on high-pollution and high-emission energy sources, such as oil and coal [2]. Second, environmental regulation favors green products and stimulates production activities to choose more high-quality and efficient energy sources as inputs, thereby resulting in a more economical and intensive production system [3]. Therefore, increasing clean energy consumption is consistent with the objectives of environmental governance in various countries. As an important bridge from traditional fossil energy to clean and renewable energy, natural gas has been important in reducing carbon emissions and to sustainable development [4]. Expanding natural gas consumption has also become a strategic option for optimizing the energy structure and decarbonizing energy systems around the world [5]. 
In the past ten years, the Chinese government has promised to create a cleaner, lower carbon and more efficient energy system by reducing carbon emissions and preventing environmental pollution [6]. Natural gas consumption in China increased from 34 billion cubic meters $(\mathrm{bcm})$ in 2003 to $280.3 \mathrm{bcm}$ in 2018 at an average annual growth rate of $17.7 \%$ and natural gas accounts for $7.8 \%$ of the primary energy mix [7]. This result is not only due to the promotion of China's coal-to-gas switching project but also related to China's Air Pollution Control Action Plan. The International Energy Agency (IEA) argued that since 2010, global carbon emissions have decreased by more than 500 million tons because of increased gas consumption, with China and the United States benefiting the most [8]. It is not difficult to conclude that promoting the growth of natural gas consumption through environmental regulation policies will be an important issue for future environmental governance.

The unexpected large-scale natural gas supply shortages, however, at the end of 2017 and the beginning of 2018 in China triggered controversy and reflection concerning the coal-to-gas policy. The cost effect caused by the mandatory policy has dampened the enthusiasm of producers and is, ultimately, not conducive to stable economic growth and environmental protection. [9,10]. In addition, because of the Chinese decentralized system, local governments are clearly competitive when making environmental policy. Under the pressure of environmental performance evaluation, local governments tend to lock in and hinder the cross-regional outflow of resources [11,12], thereby aggravating the allocation imbalance of natural gas resources among the provinces. Two questions need to be answered: (1) How does environmental regulation affect China's natural gas consumption? (2) How does the competitive nature of environmental regulation affect China's natural gas consumption?

The rest of the paper is organized as follows: Section 2 reviews current studies on the impacts of environmental regulation on energy consumption and its possible influence mechanism. Section 3 introduces the models and related variables. Empirical results are reported in Section 4, followed by discussion and policy implications in Section 5.

\section{Literature Review}

Most current studies have tried to explore the factors that affect gas consumption under environmental pressure and carbon emission constraints; such factors include the industrial structure, energy structure, infrastructures and regulated price. Chai (2018) has argued that economic growth, energy structure adjustment and the increase of urban population are the main drivers of China's gas consumption [13]. Wang (2014) and Zhang (2018) have shown that gas consumption is constrained by the demand elasticity of different sectors, while gas price has a long-term effect [14,15]. Furthermore, as has been confirmed by Li et al. (2017), the length and density of the gas pipeline has been the main obstacle to the expansion of gas market scale [16]. Cheng (2014), Lin (2016) and Liu (2018) have advised that price deregulation and reduction of subsidies would benefit the optimal allocation of gas resources by displacing coal and oil [17-19]. However, price deregulation and reduction of subsidies also increase the gas consumption cost for end-users [20].

Apart from common price subsidies and price control policies, the most representative natural gas promotion measure in China is the coal-to-gas policy. However, based on quasi-natural experiments in the Beijing-Tianjin-Hebei region of China, Shi et al. (2018) found that although the coal-to-gas policy has improved the utilization of natural gas in the urban industrial sector, the high cost of energy replacement in the civil sector, especially in rural areas, has led to large-scale energy-saving behavior. Therefore, the change direction of natural gas consumption in the industrial sector and the civil sector is the opposite. Therefore, the policy cannot effectively promote the transformation of the energy consumption structure [10]. Therefore, China needs to explore new ways to promote energy conservation and emission reduction by increasing natural gas consumption. We found that current studies have clearly proved the importance of natural gas in reducing pollution emissions and improving air quality $[21,22]$. However, few studies have discussed the internal mechanism by which environmental policies affect natural gas consumption. Zhou et al. (2017)'s research on the mechanism by which environmental regulation affects coal consumption provides an important reference for our 
study. The authors found that environmental regulation has not only a direct inhibitory effect but also an indirect effect on coal consumption through intermediary variables, such as the industrial structure and coal price [23]. Based on the above research and the substitution relationship between natural gas and coal [24], we propose three influence mechanisms (or paths) by which environmental regulation influences natural gas consumption: Path 1, environmental regulation policies affect natural gas consumption by decreasing coal consumption.; Path 2, environmental regulations adjust the energy consumption structure and affect natural gas consumption by guiding energy selection in production departments and changes in the industrial structure (especially in industrial departments); Path 3, environmental regulation makes the cost of environmental pollution caused by energy consumption endogenous to the energy market price and guides the change of the energy consumption structure through the market mechanism to affect natural gas consumption.

Environmental regulation is a broad concept and a collection of many specific environmental regulation measures. The above three paths already cover the internal mechanism of various environmental regulation measures affecting energy consumption, but these paths do not reflect the institutional characteristics of environmental regulation as government governance. Interprovincial competition in implementing environmental regulation policy under the Chinese decentralized system has always been a research topic of intense interest, and many studies have proved that China's environmental regulation competition exogenously affects the effectiveness of environmental governance $[25,26]$. Zhang et al. (2017) utilized a spatial Dobbin model to observe the effect of environmental regulation on emission reduction in China. The results showed that environmental regulation could not effectively reduce carbon emissions subject to local government competition resulting from China's fiscal decentralization and that local governments tend to ignore the negative externalities of environment regulation under the performance evaluation of economic growth, thereby resulting an increase not decrease in overall carbon emissions [25]. Zhu et al. (2011) studied the spatial interaction between foreign direct investment (FDI) and environmental policy under local decentralization by using spatial econometric techniques, and the authors determined that the behavior of local governments is heterogeneous about the choices and trade-offs between environmental regulation and FDI; the authors also determined that environmental regulation results in a top-to-bottom or bottom-to-bottom effect [26]. Zhu et al. (2018) explored the effect of the interaction between local government competition and environmental regulation on regional air pollution by using a panel model and a spatial Durbin model. The results showed that local government competition leads to significant spatial effects of environmental regulation on regional air pollution [27]. Therefore, the Chinese-style decentralized system drives local governments to adopt strategies, such as top-to-top, bottom-to-bottom, and differentiated competition in environmental performance evaluation tournaments. Based on the current research, we speculate that environmental regulation space competition, as an exogenous condition, affects the regional environmental regulation intensity and the spatial flow and allocation of natural gas resources. Moreover, different forms of competition in environmental regulation (such as top-to-top, bottom-to-bottom or differentiated competition [28]) have different effects.

In summary, the following three objectives can be derived from the above literature: first, determining how environmental regulation affects regional gas consumption by focusing on the change in the energy structure; second, focusing on regional heterogeneity and exploring how the evolution of environmental regulation law has promoted gas consumption; and third, revealing the mechanism of environmental regulation competition based on the gas resource flow. Therefore, this paper will be focused on these three issues: (a) how environmental regulation promotes the growth of natural gas consumption through energy substitution, (b) the conduction path of the spatial spillover effect of the regulation and (c) the impact of local governments' choice of regulation on the allocation path of the natural gas market under a decentralized system. For the abovementioned reasons, the hypothesis of the impact mechanism of environmental regulation on natural gas consumption in China is proposed in this paper, as shown in Figure 1. 


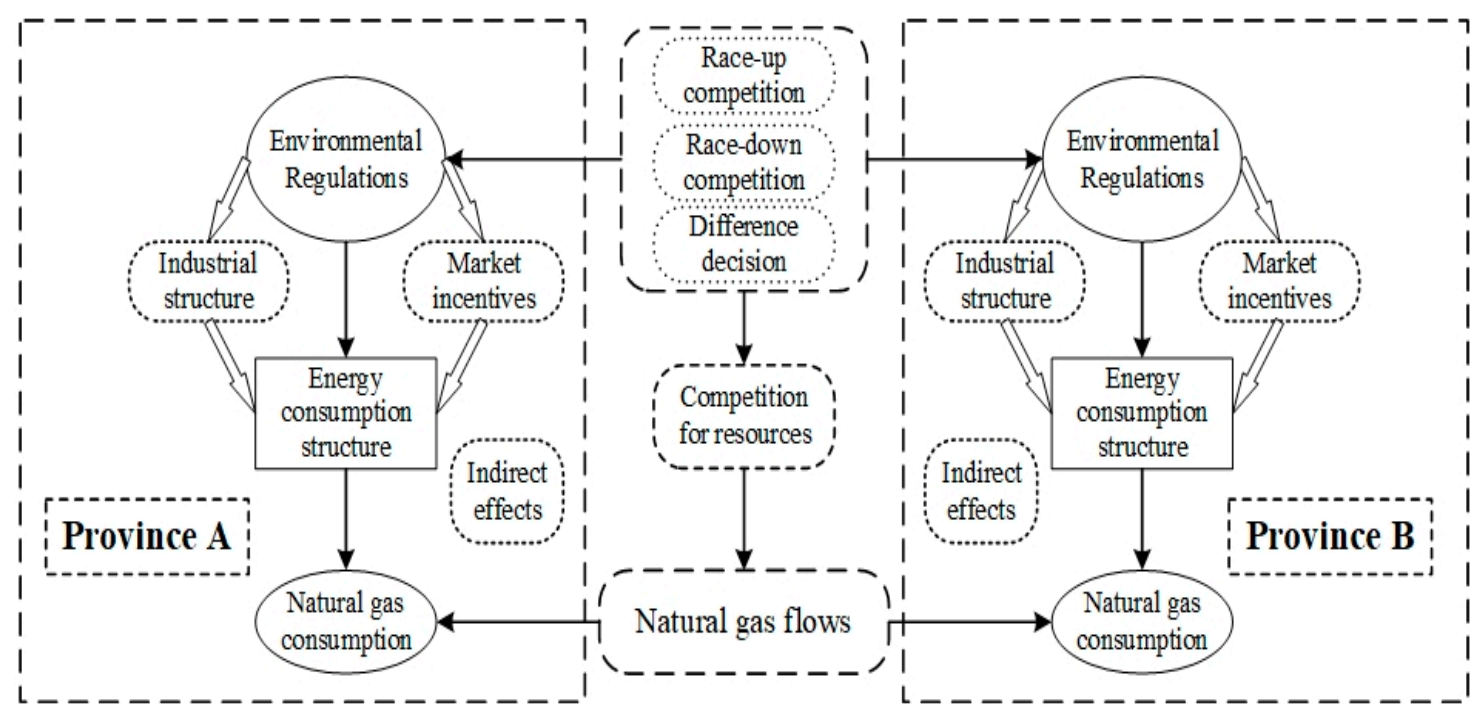

Figure 1. Impact of environmental regulations on natural gas consumption.

\section{Model and Data}

\subsection{Empirical Model}

Nonspatial panel models (see Equations (1) and (2)) are developed to explore the conduction path of environmental regulation on gas consumption within regions without considering the spillover effects mainly due to policy makers' concern for the improvement of local environmental quality under the Chinese decentralized system. In Equation (1), GCO it is the interpreted variable denoted as the gas consumption of $i$-th region at time $t . E R_{i t}$ is the core explanatory variable denoted as environmental regulation intensity, and $E C S_{i t}, I_{n} d_{i t}, O_{i l} P_{i t}$ and $X_{i, t, k}$ are denoted as the energy consumption structure, industrial structure, substituted energy price and the control variables, respectively. $\mu_{i}, \eta_{t}$ and $\varepsilon$ are denoted as the individual fixed effect, time-fixed effect and random term, respectively. Additionally, in Equation (2), the square and the cubic term of regulation intensity are set up to test whether there is a " $S$ " or " $N$ " nonlinear relationship between regulation intensity and gas consumption within regions in China [29].

$$
\begin{aligned}
\ln \left(G C O_{i t}\right) & =\alpha_{1} \ln \left(E R_{i t}\right)+\alpha_{2} \ln \left(E R_{i t}\right) \times \ln \left(E C S_{i t}\right)+\alpha_{3} \ln \left(E R_{i t}\right) \times \ln \left(\text { Ind }_{i t}\right) \times \ln \left(E C S_{i t}\right) \\
& +\alpha_{4} \ln \left(E R_{i t}\right) \times \ln \left(O i l P_{i t}\right) \times \ln \left(E C S_{i t}\right)+\beta_{k} \sum_{k=1}^{m} \ln \left(X_{i, t, k}\right)+\mu_{i}+\eta_{t}+\varepsilon \\
\ln \left(G C O_{i t}\right) & =\alpha_{1} \ln \left(E R_{i t}\right)+\alpha_{2} \ln \left(E R_{i t}\right)^{2}+\alpha_{3} \ln \left(E R_{i t}\right)^{3}+\beta_{k} \sum_{k=1}^{m} \ln \left(X_{i, t, k}\right)+\mu_{i}+\eta_{t}+\varepsilon
\end{aligned}
$$

The spatial Dubbin model [30,31] is also introduced in this paper to evaluate the regulation's spatial spillover effects on gas consumption that compose the overestimation or underestimation of the regulation effects from the nonspatial panel models. The spatial Dubbin model (SDM) is formulated in Equation (3), and two spatial weight matrixes are to be chosen in the SDM: an adjacency and economic geographical matrix. The former matrix consists of 1 for neighboring regions and 0 for nonadjacent ones. The latter matrix is calculated as $W_{e}=W_{d} \cdot \operatorname{diag}\left(\bar{E}_{1} / \bar{E}_{,} \bar{E}_{2} / \bar{E}_{,} \ldots, \bar{E}_{n} / \bar{E}\right)$, where $W_{d}$ is the spherical distance matrix between two regions and $\bar{E}_{i}$ is the annual average GDP of $i$-th region from 2005 to 2017. 


$$
\begin{aligned}
\ln \left(G C O_{i t}\right) & =\delta W * \ln \left(G C O_{i t}\right)+\alpha_{1} \ln \left(E R_{i t}\right)+\alpha_{2} W * \ln \left(E R_{i t}\right)+\alpha_{2} \ln \left(E R_{i t}\right) \times \ln \left(E C S_{i t}\right) \\
& +\alpha_{3} \ln \left(E R_{i t}\right) \times \ln \left(I n d_{i t}\right) \times \ln \left(E C S_{i t}\right)+\alpha_{4} \ln \left(E R_{i t}\right) \times \ln \left(O i l P_{i t}\right) \times \ln \left(E C S_{i t}\right) \\
& +\alpha_{5} W * \ln \left(E R_{i t}\right) \times \ln \left(E C S_{i t}\right)+\alpha_{6} W * \ln \left(E R_{i t}\right) \times \ln \left(I n d_{i t}\right) \times \ln \left(E C S_{i t}\right) \\
& +\alpha_{7} W * \ln \left(E R_{i t}\right) \times \ln \left(O i l P_{i t}\right) \times \ln \left(E C S_{i t}\right)+\beta_{k} \sum_{k=1}^{m} \ln \left(X_{i, t, k}\right)+\mu_{i}+\eta_{t}+\varepsilon
\end{aligned}
$$

\subsection{Variables and Data}

$\mathrm{GCO}_{i t}$ is expressed as the gas consumption volume of province i in $t$ year (unit: bcm/a). The intensity of environmental regulation is the core variable in the above models and is generally related to investment in environmental governance [32]. $E R_{i t}$ is formulated as $E R_{i t}=\left(I_{i t} / \overline{I_{t}}\right) /\left(P_{i t} / \overline{P_{t}}\right)$, where $I_{i t}$ is the investment of $i$-th province in year $t$ for industrial waste gas treatment, $\overline{I_{t}}$ is the average value of $I_{i t}, P_{i t}$ is the waste gas emission volume in $i$-th province in year $t$, and $\overline{P_{t}}$ is the average annual value of $P_{i t}$.

In addition, the investment comes mainly from financial subsidies, sewage charges (taxes) and consumption taxes on refined oil, and then the government can transform enterprise sewage charges into clean energy subsidies via transfer payments and uses a refined oil consumption tax as a market incentive to leverage energy consumption prices. Thus, $E R_{i t}$ can evidently reflect the government's preference for environmental governance measures and strategies and also impact the path affecting gas consumption.

Control variables $X_{i t}$ are briefly described as follows: (a) GDP is the level per capita of the carrying capacity and purchasing power of natural gas; (b) GasPop is the proportion measuring the scale of residential gas consumption of the gas consumption population in the urban population; (c) considering that industry is the main contributor to energy consumption, Ind is expressed as the ratio of industrial added value to GDP; (d) ECS is the ratio of the sum of coal and oil consumption to primary energy consumption, and this ratio can be used to measure the energy consumption dependence on highly polluting energy; (e) Pipeline_Length is the total length of the gas transmission pipeline within the province and can serve as a measure of the gas infrastructure promoting gas consumption; (f) GasPrice is the average gas price for end users from provinces in China and is calculated by the weights of the industrial, residential and commercial gas price; and (g) OilPrice is the provincial refined oil price that indirectly affects the price mechanism in the energy substitution.

The data on energy consumption are from the energy balance tables of all provinces in the China Energy Statistics Yearbook from 2006 to 2018. The air pollution governance data are from the China Environmental Yearbook from 2006 to 2018. The energy prices are from the China Price Statistics Yearbook and EPS database from 2006 to 2018. The data on the gas consumption population and pipeline length are from the EPS and CEIC databases. Other data are from the China Statistical Yearbook from 2006 to 2018. Due to the lack of data and inconsistent statistical caliber, this paper selects 30 provinces, excluding Tibet, Hong Kong, Macao and Taiwan, as the research cases.

\section{Results}

\subsection{Conduction Path of Environmental Regulation Effects}

Models I VIII are proposed to explore the nonlinear relationship between environmental regulation and gas consumption within regions and the conduction paths of the regulation effect. The results are listed in Table 1. 
Table 1. Estimated results of the impact of environmental regulations on natural gas consumption.

\begin{tabular}{|c|c|c|c|c|c|c|c|}
\hline \multirow{2}{*}{ Variable (ln) } & Model I & Model II & Model III & Model IV & Model V & Model VI & Model VII \\
\hline & (1) & (2) & (3) & (4) & (5) & (6) & (7) \\
\hline$E R$ & 0.0054 & 0.0352 & 0.0610 * & 0.0181 & 0.0354 & -0.0008 & 0.0295 \\
\hline$E R^{\wedge} 2$ & & 0.0323 * & $-0.0628 *$ & & & & \\
\hline$E R \wedge 3$ & & & $-0.0350 * *$ & & & & \\
\hline$E R^{*} E C S$ & & & & $0.1702 * *$ & & & 0.0830 \\
\hline$E R^{*} I n d^{*} E C S$ & & & & & $-0.3728^{* *}$ & & -0.3024 * \\
\hline$E^{*}$ OilPrice $^{*} E C S$ & & & & & & 1.5185 & -3.4334 \\
\hline Ind ${ }^{*} E C S$ & $-0.1840 *$ & $-0.206^{*}$ & $-0.2603 *$ & $-0.2508 *$ & $-0.2296^{*}$ & -0.1576 & -0.2443 \\
\hline GDP & $0.5571^{* * *}$ & $0.5385^{* * *}$ & $0.5505^{* * *}$ & $0.6659^{* * *}$ & $0.6701^{* * *}$ & $0.6732^{* * *}$ & $0.6664^{* * *}$ \\
\hline GasPop & $0.0452 *$ & $0.0444 *$ & $0.0318 *$ & $0.0495 *$ & $0.0563 *$ & $0.0722 *$ & 0.0490 \\
\hline Ind & -0.2958 & -0.2605 & -0.2994 & -0.3759 * & $-0.3645 *$ & $-0.3493 *$ & $-0.3566^{*}$ \\
\hline ECS & $-0.8128^{* * *}$ & $-0.8201 * * *$ & $-0.8101^{* * *}$ & $-0.7470 * * *$ & $-0.7450 * * *$ & $-0.7498^{* * *}$ & $-0.7523 * * *$ \\
\hline OilPrice & 0.4071 ** & $0.4142 * *$ & $0.3842 * *$ & -0.0991 & 0.1875 & -0.0891 & 0.1077 \\
\hline GasPrice & $-0.7833 * * *$ & $-0.7591 * * *$ & $-0.7854^{* * *}$ & $-0.7001^{* * *}$ & $-0.7215^{* * *}$ & $-0.7165^{* * *}$ & $-0.7144^{* * *}$ \\
\hline PipelineLen & $0.4875^{* * *}$ & $0.4974^{* * *}$ & $0.4999 * * *$ & $0.4982 * * *$ & $0.4938^{* * *}$ & $0.4748^{* * *}$ & $0.4988^{* * *}$ \\
\hline Rbar $^{2}$ & 0.7116 & 0.7117 & 0.7139 & 0.7104 & 0.7104 & 0.7069 & 0.7096 \\
\hline Sigma ${ }^{2}$ & 0.3025 & 0.3024 & 0.3001 & 0.3039 & 0.3038 & 0.3075 & 0.3046 \\
\hline
\end{tabular}

The first, square and cubic term of $\ln E R$ are gradually added into Equation (1) to formulate Models I-III as shown in the second to fourth columns of Table 1. The table shows that the coefficients of the regulation intensity in Model III are significant compared with those in Models I and II, and even the first coefficient is negative, the second is positive and the third is negative, thus indicating that there is an inverted " $N$ " curve between the gas consumption volume and the regulation intensity (depicted in Figure 2); there are two inflection points: -1.48 and 0.50. As Figure 2 shows, regulation enhances gas consumption if the $\ln E R$ is in the range of $-1.48-0.50$; otherwise, regulation reduces the gas volume within regions, thus resulting in a "green paradox". Further, in Figure 3, the averages of the intensities during three periods-2005-2009, 2010-2013 and 2014-2017-show the intensity changes in each province in China from 2015 to 2017, and the $\ln E R$ of most provinces are in the range of $-1.48-0.5$, thus indicating that under the pressure of environmental assessment by the central government, local governments have the demand to increase gas consumption. However, the intensity of regulation varies greatly among the provinces, and the five provinces of Beijing, Tianjin, Fujian, Shanxi and Shandong, especially, have been maintaining high regulation because the $\ln E R$ of these provinces are greater than zero, while other provinces in China maintain low regulation. Additionally, the difference is that the provinces with high intensity tend to gradually weaken in intensity, while those with low intensity tend to strengthen in intensity. Therefore, the changes and differences among the provinces indirectly indicate the difficulty of local governments in balancing and choosing between environmental quality improvement and economic development.

The interaction items $\ln \left(E R^{*} E C S\right), \ln \left(E R^{*} I n d^{*} E C S\right)$ and $\ln \left(E R^{*}\right.$ OilPrice $\left.E C S\right)$ are added consecutively to Model I to explore the conduction paths of the effect of regulation on gas consumption, and Models IV VI are shown in the fifth to seventh columns of Table 1.

The coefficient $\ln \left(E R^{*} E C S\right)$ in Model IV is significantly positive, thus indicating that regulation is conducive to enhancing gas consumption through internalization of the environmental cost of coal combustion to control coal consumption; this finding is consistent with the findings of Zhou et al. (2017). As Model V shows, instead of increasing gas consumption, regulation significantly negatively affects gas consumption along the conduction path of "ER-Ind-ECS", thereby resulting in the green paradox. In Model VI, the coefficient $\ln \left(E R^{*} O i l\right.$ Price $\left.E C S\right)$ is not significant but positive, thus showing that environmental regulation can potentially increase natural gas consumption at the energy terminal consumption price, but the positive effect is not significant now. 


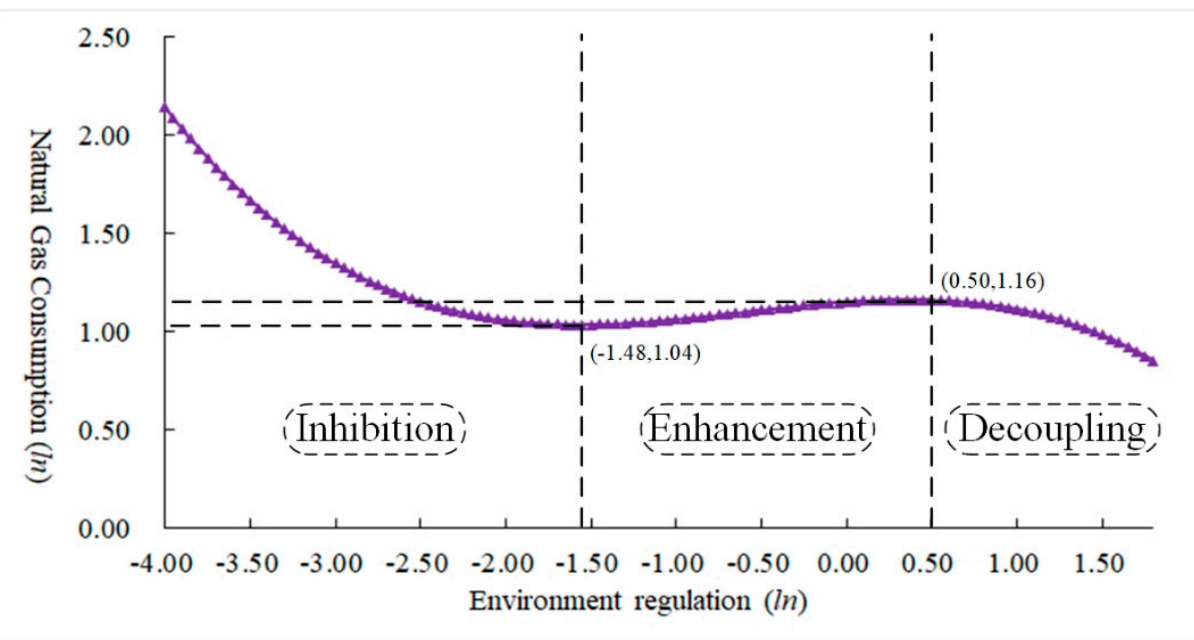

Figure 2. The inverted " $N$ " curve between gas consumption and regulation intensity.

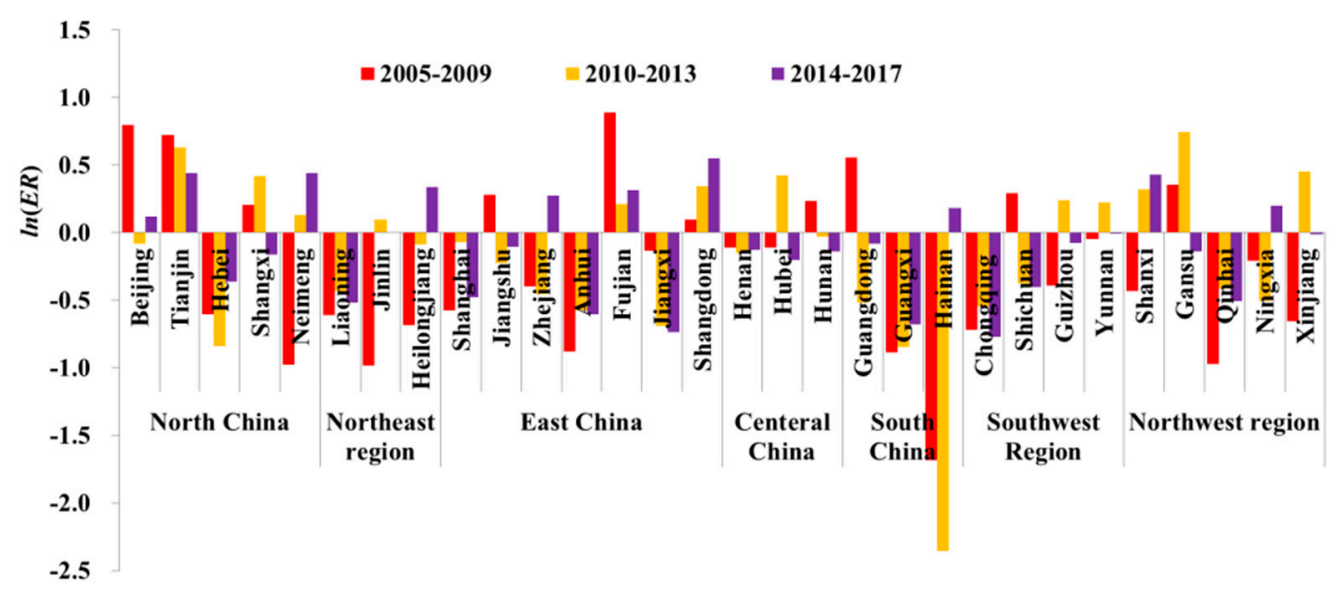

Figure 3. Distribution of the regulation intensity from 2005 to 2017.

When the three interaction items are added together to Model I to examine whether the three paths of the effects of regulation on gas consumption exist simultaneously (see Model V in Table 1), the regression results listed in the seven columns are unexpected. Only the coefficient $\ln \left(E R^{*} \operatorname{In} d^{*} E C S\right)$ is significant and positive; the coefficient $\ln \left(E R^{*}\right.$ OilPrice $\left.^{*} E C S\right)$, especially, is negative (as is not the case in Model VI). These results indicate that the effect of regulation on the oil industry weakens the direct effect of $E R$ on the energy consumption structure and even produces the inverse substitution effect of natural gas on refined oil in the energy market.

In addition to the abovementioned variables, most of the control variables in each model are significant state variables, and the changes in the coefficients are extremely small, thus indicating that the econometric models proposed in this paper are robust. Concretely, the coefficient $\ln (G D P)$ is significantly positive, thus reflecting that economic growth in China will drive the growth of natural gas consumption. The coefficients of $\ln ($ GasPop) and $\ln$ (PipelineLen) are also significantly positive; i.e., China's urbanization and pipeline network construction will further enhance the gas consumption and space of urban residents. However, the coefficient $\ln (\operatorname{Ind})$ is significantly negative because of the high dependence of China's industrial production on coal consumption. Therefore, it is also difficult for China to improve energy utilization efficiency and the transformation of the energy structure [6]. Additionally, the coefficient $\ln$ (GasPrice) is significantly negative, and the coefficient $\ln$ (OilPrice) is positive, thus indicating that the gas price is currently high, will reduce gas consumption volumes, and thus cannot effectively replace refined oil in the energy market. 


\subsection{Spillover Effects of Environmental Regulation}

\subsubsection{Spatial Correlation Analysis}

To explore the spatial correlation of environmental regulation and natural gas consumption and, specifically, for each of the 30 provinces in China, the univariate and bivariate Moran indices are introduced in this paper (see Equation (4)) [33,34].

$$
B M I=\frac{n}{S_{0}} \frac{z_{1}{ }^{\prime} W z_{2}}{z_{1} z_{2}}
$$

where $n$ is the number of regions; $S_{0}$ is the sum of the elements of the weight matrix; and $z_{1}$ and $z_{2}$ are the normalized value of the natural gas consumptions and regulation intensities, respectively, the results, which are listed in Table 2, are as follows.

Table 2. The global correction of gas consumption and environmental regulation.

\begin{tabular}{|c|c|c|c|c|c|c|}
\hline \multirow{2}{*}{ Year } & \multicolumn{3}{|c|}{ Adjacent Matrix } & \multicolumn{3}{|c|}{ Economic Geography Matrix } \\
\hline & $\begin{array}{c}\text { Gas } \\
\text { Consumption }\end{array}$ & Regulation & $\begin{array}{c}\text { Gas } \\
\text { Consumption- } \\
\text { Regulation }\end{array}$ & $\begin{array}{c}\text { Gas } \\
\text { Consumption }\end{array}$ & Regulation & $\begin{array}{c}\text { Gas } \\
\text { Consumption- } \\
\text { Regulation }\end{array}$ \\
\hline 2005 & $0.3817^{* * *}$ & -0.0728 & $0.2909 * *$ & $0.0599 * *$ & 0.0027 & $0.3125^{* * *}$ \\
\hline 2006 & $0.1966^{* *}$ & -0.1755 & $0.2437^{*}$ & $0.0357^{*}$ & -0.0567 & $0.2725 * *$ \\
\hline 2007 & $0.1467 * *$ & $0.1032 *$ & 0.1181 & $-0.0731 *$ & -0.0102 & 0.1608 \\
\hline 2008 & $0.1579 * *$ & -0.0068 & 0.1224 & -0.0931 & $0.0936^{* *}$ & $0.3607^{* * *}$ \\
\hline 2009 & 0.1049 * & $-0.1811^{*}$ & -0.1601 & -0.1153 & -0.0409 & $0.2317^{*}$ \\
\hline 2010 & $0.1320 * *$ & -0.0079 & $-0.2701^{* *}$ & -0.1057 & 0.0213 & 0.2176 * \\
\hline 2011 & $0.1627 * *$ & $0.0633 *$ & $0.3906^{* * *}$ & -0.0933 & -0.0178 & 0.1485 \\
\hline 2012 & $0.2035^{* *}$ & -0.0699 & $0.3895^{* * *}$ & -0.0803 & -0.0311 & $0.2457^{*}$ \\
\hline 2013 & $0.1846^{* *}$ & -0.0129 & -0.0029 & -0.0718 & -0.0601 & 0.0433 \\
\hline 2014 & 0.1320 ** & -0.0238 & 0.0418 & -0.0719 & 0.0087 & 0.1510 \\
\hline 2015 & $0.1798^{* *}$ & 0.00014 & $0.2582 *$ & $-0.0619 *$ & -0.0868 & $0.2171^{* *}$ \\
\hline 2016 & $0.1396^{* *}$ & $0.1412 * * *$ & $0.2574 *$ & -0.0614 * & $0.0569 *$ & $0.1415 *$ \\
\hline 2017 & $0.1697^{* *}$ & $0.1327^{* *}$ & $0.3419^{* * *}$ & -0.0479 & $0.1382^{* * *}$ & 0.0215 \\
\hline Average & $0.1369 * *$ & $0.0954 *$ & $0.3212^{* * *}$ & -0.0967 & 0.0189 & 0.2114 * \\
\hline
\end{tabular}

Gas consumption in China shows significant spatial autocorrelation under the adjacent matrix but shows negative autocorrelation and is insignificant under the economic geography matrix, thereby indicating that gas consumption in one region positively affects the adjacent regions. From 2005 to 2017, although the spatial autocorrelation of environmental regulation was both positive and negative, gas consumption in China showed significant positive correlation on the whole, and the correlation under the adjacent matrix was greater than that under the economic geography matrix. This phenomenon shows that with the strengthening of the regulation assessment, there is a competition between local governments over environmental regulation.

Furthermore, the externality caused by competition and changes in environmental regulation leads to a close spatial correlation between environmental regulation and natural gas consumption. Before 2009, the correlation under the economic geography matrix was higher than the correlation under the neighboring matrix because long-distance gas transmission pipelines, such as the West-East Gas Transmission Pipeline, the Shaanxi-Beijing Line and the Sichuan-East Gas Transmission Pipeline, were completed successively from 2005 to 2009. Natural gas flowed mainly across regions. Therefore, environmental regulations affected the spatial distribution of natural gas resources along the long-distance gas transmission pipeline.

However, since 2010, the gas pipelines in China's provinces have been continuously improved, and the interconnection between the pipelines in the provinces has increased. Therefore, environmental 
regulations affect mainly the allocation of natural gas resources between neighboring regions. Therefore, China's natural gas consumption and environmental regulation have significant spatial positive correlation under the adjacency matrix, and the externality of regulation affects the spatial allocation of natural gas resources.

The LISA method is introduced in this paper to further examine the local spatial correlation of gas consumption and environmental regulation intensity; the correlations are illustrated in Figure 4.

As Figure 4a shows, the Beijing, Hebei, Shannxi, Henan, Shangdong, Jiangsu, Zhang and Shanghai and Xinjiang provinces form a high-high agglomeration area (denoted as $\mathrm{HH}$ ) for gas consumption. In contrast, the Yunnan, Guangxi and Hunan provinces form a low-low gathering area, denoted as LL. Xinjiang, Sichuan and Guangdong have high gas consumption, thus forming a high-low agglomeration area (denoted as HL) with the surrounding provinces, while Gansu and Anhui provinces (which have low gas consumption) form a low-high agglomeration with the surrounding provinces.

According to Figure $4 \mathrm{~b}$, environmental regulations between neighboring provinces in northern and northwestern China (Xinjiang, Qinghai, Gansu, Inner Mongolia, Beijing and Hebei) are all high regulation intensity areas, and top-to-top competitions emerge within these provinces, so these areas can be denoted as $\mathrm{HH}$; these areas are similar to the gas consumption agglomeration area. The regulation intensities among neighboring provinces in the southeast and central regions (Jiangsu, Zhejiang, Shanghai, Fujian, Hubei, Hunan, Anhui and Jiangxi) are all low, thus implying the bottom-to-bottom competition employed by the local governments among these provinces, denoted as LL. However, in other provinces, the regulation shows a high-low or low-high agglomeration, thus implying that decisions regarding provincial environmental regulation have discrepancies. For example, Sichuan, Henan, Jilin and the surrounding areas are an HL agglomeration, while Guizhou, Shandong and the surrounding areas are an LH agglomeration.

Furthermore, the spatial structure of gas consumption agglomeration in China is dominated by the spatial correlation of environmental regulation (as shown in Figure 4), especially in regions with insignificant spatial correlation in Inner Mongolia, Hubei, Jiangxi, Zhejiang, Fujian and other provinces. Under the effect of environmental regulation, these provinces show significant spatial positive correlation compared with that shown in Figure 4a. Concretely, the area with an $\mathrm{HH}$ agglomeration is mainly in Xinjiang, Inner Mongolia, Sichuan and Shaanxi in northwest China, and these provinces have high gas consumption and are surrounded by provinces, such as Beijing, Hebei and Shanxi, with relatively high regulation intensity. The area with an LL agglomeration is mainly in the Hunan, Hubei, Anhuia and Guangxi provinces in the central and southern regions of China, and these provinces with low natural gas consumption are surrounded by provinces (such as Shanghai, Jiangsu and Zhejiang) with relatively low regulation intensity.

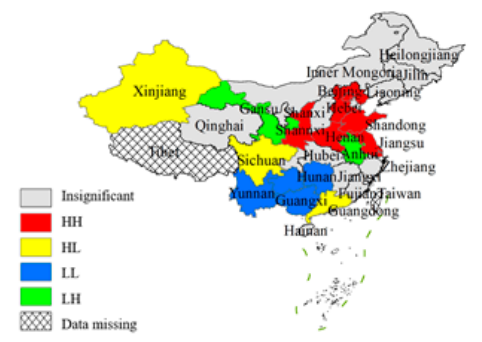

(a) Gas consumption LISA Map

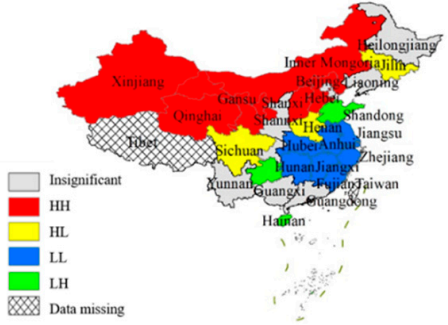

(b) Regulation LISA Map

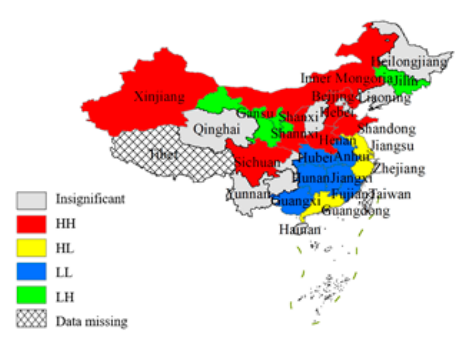

(c) Gas consumption-regulation LISA Map

Figure 4. LISA maps of regulation intensity (average from 2005 to 2017).

\subsubsection{Spatial Effects at the National Level}

The spatial spillover effect and path of environmental regulation on gas consumption at the national level (as shown in Table 3 ) are examined by using Models VIII XII proposed in this paper by 
adding the space lag term of environmental regulation into Models IV VII. The difference between the control variable coefficients of Model VIII XII is small, thus indicating that the model is robust.

Table 3. Spatial spillover effects of environmental regulation on gas consumption at the national level.

\begin{tabular}{|c|c|c|c|c|c|}
\hline \multirow{2}{*}{ Variable (ln) } & Model VIII & Model IX & Model X & Model XI & Model XII \\
\hline & (1) & (2) & (3) & (4) & (5) \\
\hline$E R$ & -0.0026 & 0.0065 & 0.0171 & -0.0044 & 0.0179 \\
\hline$E R^{*} E C S$ & & $0.1388^{* *}$ & & & 0.1001 \\
\hline$E R^{*} I n d^{*} E C S$ & & & $-0.3094^{* *}$ & & -0.1978 \\
\hline ER $^{*}$ OilPrice ${ }^{*}$ ECS & & & & 2.0976 * & $2.8692 * *$ \\
\hline $\operatorname{Ind} d^{*} E C S$ & -0.1988 & $-0.3883 *$ & $-0.4055^{*}$ & -0.2449 & $-0.4949 *$ \\
\hline GDP & $0.6309 * * *$ & $0.6219^{* * *}$ & $0.6244^{* * *}$ & $0.6303^{* * *}$ & $0.6224^{* * *}$ \\
\hline GasPop & $0.1241^{* *}$ & $0.0913 *$ & $0.0923 *$ & $0.1282 * *$ & $0.0869 *$ \\
\hline Ind & -0.2799 & $-0.3492 * *$ & $-0.3297 * *$ & $-0.3021 *$ & $-0.3749 * *$ \\
\hline ECS & $-0.6649 * * *$ & $-0.6488^{* * *}$ & $-0.6588^{* * *}$ & $-0.6591^{* * *}$ & $-0.6519^{* * *}$ \\
\hline OilPrice & 0.1997 & 0.3066 & 0.6301 & 0.2876 & 0.6140 \\
\hline GasPrice & $-0.5533^{* * *}$ & $-0.5226^{* * *}$ & $-0.5480^{* * *}$ & $-0.537^{* * *}$ & $-0.5193^{* * *}$ \\
\hline PipelineLen & $0.4003^{* * *}$ & $0.4367 * * *$ & 0.4392 & $0.3945^{* * *}$ & $0.4420 * * *$ \\
\hline$W^{*} E R$ & -0.0492 & -0.0467 & -0.0136 & -0.0489 & -0.0313 \\
\hline$W^{*} E R^{*} E C R$ & & 0.1384 * & & & -0.0051 \\
\hline$W^{*} E R^{*} I n d^{*} E C S$ & & & $-0.4026^{* *}$ & & $-0.3741^{*}$ \\
\hline$W^{*} E R^{*}$ OilPrice $^{*} E C S$ & & & & 0.2492 & 0.1901 \\
\hline$W^{*} G C O$ & $0.2123^{* * *}$ & $0.2023^{* * *}$ & $0.1963^{* * *}$ & $0.2203^{* * *}$ & $0.2014^{* * *}$ \\
\hline Rbar $^{2}$ & 0.6981 & 0.7049 & 0.7065 & 0.6986 & 0.7086 \\
\hline log-likelihood & -306.5922 & -304.2787 & -303.9109 & -305.8222 & -302.3382 \\
\hline
\end{tabular}

$* * *, * *$ and $*$ indicate statistical significance at $1 \%, 5 \%$ and $10 \%$, respectively.

In Model VIII, the $\ln (E R)$ and $W^{*} \ln (E R)$ coefficients are not significant, thus indicating that environmental regulation does not significantly directly affect natural gas consumption and is not the source of spatial externalities. Model IX further explores the indirect impact path of environmental regulation on natural gas consumption while considering the spatial effect of environmental regulation. The coefficients $\ln (\text { ER })^{*} \ln ($ ECS $), \ln (\text { ER })^{*} \ln (\operatorname{Ind})^{*} \ln ($ ECS $)$ and $\ln (\text { ER })^{*} \ln$ (OilPrice $)^{*} \ln ($ ECS $)$ and their respective spatial lag coefficients in Model IX are significant, thus indicating that environmental regulations in surrounding areas indirectly affect local natural gas consumption through coupling with industrial structure, energy consumption structure and energy price. Therefore, the indirect effects of environmental regulations in China's provinces on natural gas consumption have externalities, thereby affecting the spatial pattern of natural gas consumption and triggering competition for natural gas resources.

In Model IX, the $\ln (E R)^{*} \ln (E C S)$ coefficient $(0.1388)$ is significantly positive and is lower than the corresponding coefficient (0.1702) in Model IV, thus indicating that this path's effect on natural gas consumption is weakened under the condition of the spatial correlation of neighboring provinces. The $W^{*} \ln (E R)^{*} \ln (E C S)$ coefficient $(0.1384)$ is significantly positive, thus indicating that China's environmental regulation policy concerning the level of coal consumption has formed a scale effect, which can effectively restrict the consumption of traditional fossil energy, such as coal from the regional level, thus improving the overall level of regional natural gas consumption.

In Model X, the $\ln (\mathrm{ER})^{*} \ln (\mathrm{Ind}) * \ln (\mathrm{ECS})$ coefficient $(-0.3094)$ and spatial lag term coefficient are both significantly negative (-0.4026), thus indicating that the regional industry adversely affects the overall level of regional natural gas consumption under strong environmental regulation. Thus, the consumption of natural gas and high-pollution energy has the same trend. China's industry depends on the consumption of high-pollution energy, such as coal.

In Model XI, the $\ln (E R)^{*} \ln (\operatorname{Ind})^{*} \ln (\mathrm{ECS})$ coefficient is significantly positive (2.0976), while the spatial lag term coefficient is not significantly positive (0.2492). Compared with the coefficient of the corresponding term in Model VI, the $\ln (\mathrm{ER})^{*} \ln (\mathrm{Ind})^{*} \ln (\mathrm{ECS})$ coefficient is not significant, thus indicating 
that the linkage mechanism of environmental policies in neighboring provinces is the premise to indirectly increase the overall natural gas consumption level in the region by increasing the price of oil.

In Model XII, the coefficients $\ln (\mathrm{ER})^{*} \ln (\mathrm{ECS})$ and $\ln (\mathrm{ER}) * \ln (\mathrm{Ind}) * \ln (\mathrm{ECS})$ are no longer significant, while the coefficient $\ln (E R)^{*} \ln (\text { OilPrice })^{*} \ln (E C S)$ is significantly positive (2.8692), and the value of the coefficient increased compared with the value of the corresponding coefficient (2.0976) in Model IX, thus indicating that environmental regulation of oil price is the most effective measure to promote local natural gas consumption under the reality that environmental regulation has spatial correlation and three mechanisms coexist. According to the spatial lag term coefficient, the coefficients $W^{*} \ln (E R)^{*} \ln (E C S)$ and $W^{*} \ln (\text { ER })^{*} \ln (\text { OilPrice })^{*} \ln ($ ECS $)$ are not significant, while the coefficient $W^{*} \ln (\text { ER })^{*} \ln (\operatorname{Ind})^{*} \ln ($ ECS $)$ is significantly negative, thus indicating that the spatial externalities of the three mechanisms overlap and conflict.

\subsubsection{Spatial Effects at the Regional Level}

Further analysis is performed on the mechanism of the different impacts of environmental regulation on natural gas consumption within regions with different forms of competition for environmental regulation according to the different forms of spatial agglomeration of environmental regulation intensity, as shown in Figure $5 \mathrm{The} \mathrm{HH}$ region with concentrated high regulation intensity is distributed mainly in the provinces in western and northeastern China, while the LL region is in the southeast coastal and central provinces in China; other HL and LH areas are distributed in only a few provinces, specifically, Yunan, Shangdong, Chongqing, Henan and Jilin. The former two areas are analyzed by using spatial econometric Models VIII and XII, and their results are shown in Table 4.

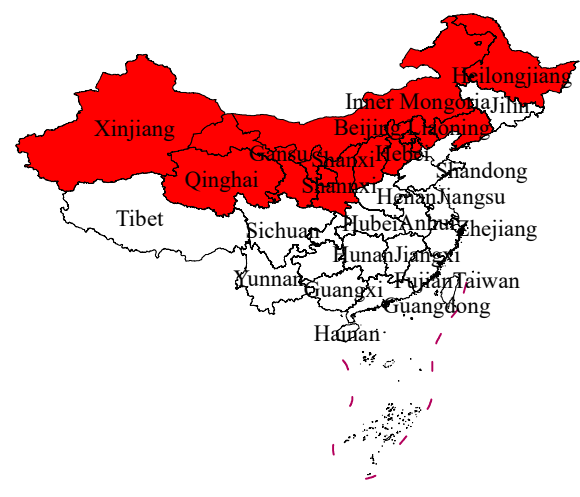

a. HH

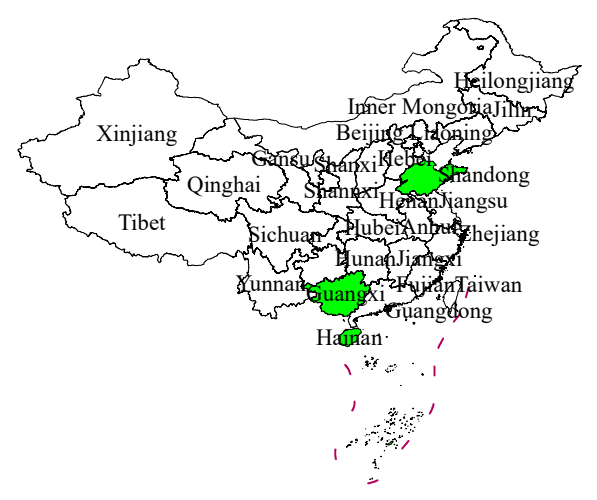

c. HL

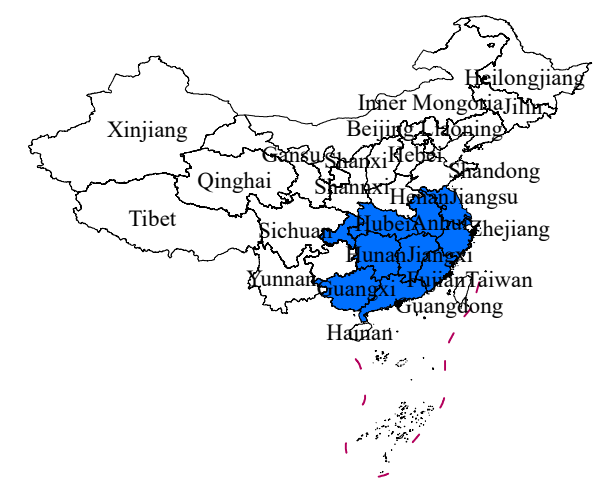

b. $\mathbf{L} \mathbf{L}$

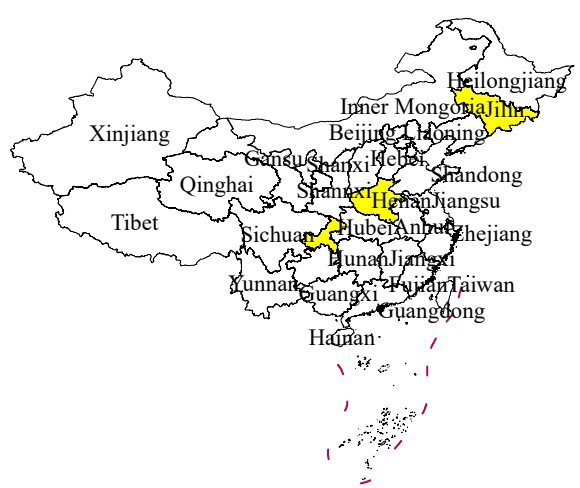

d. LH

Figure 5. Spatial distribution of environmental regulation intensity. 
For the $\mathrm{HH}$ region, environmental regulation has inhibited natural gas consumption to some degree through top-to-top competitions between provinces within this region because of the significantly negative effect of the coefficient $\ln (E R)$; this effect is not unlike the effect of environmental regulation on gas consumption at the national level, as shown in Table 3. Additionally, industrial energy consumption in this region has obviously been shifting to natural energy consumption in the context of high environmental regulation intensity; this shift to natural energy consumption will gradually strengthen the coupling degree between natural gas and industrial production. The spatial spillover effect of environmental regulation will decrease the natural gas consumption of neighboring provinces in that the three coefficients $W^{*} \ln (E R)^{*} \ln (E C S), W^{*} \ln (E R)^{*} \ln (\operatorname{In} d)^{*} \ln (E C S)$ and $W^{*} \ln (E R)^{*} \ln (\text { OilPrice })^{*} \ln (E C S)$ are significantly negative. Therefore, it is predicted that high-intensity regulation will trigger local governments in this region to compete for more natural gas resources. This competition will help promote the economic and social development of this region with low carbonization.

For the LL region, lowering environmental regulations is obviously beneficial for increasing natural gas consumption in this region and for the low carbonization of the energy consumption structure, increasing natural gas consumption in the industrial field and accelerating natural gas substitution in the energy market. As implied by the spatial lag coefficient, the environmental regulation policy will be imitated by the governments of neighboring regions to lower the regulation intensity, and so there is a trend in this region towards competing to relax environmental regulation. Although the coefficients $W^{*} \ln (E R)^{*} \ln (E C S), W^{*} \ln (E R)^{*} \ln (\text { Ind })^{*} \ln (E C S)$ and $W^{*} \ln (E R)^{*} \ln (\text { OilPrice })^{*} \ln (E C S)$ are not significant, the first and second items are negative, while the third item is positive, thus indicating that environmental regulation is reduced. Expectedly, if environmental regulation is reduced, the spillover effect of environmental regulation can promote the overall increase of natural gas consumption in this region, but reducing environmental regulation is likely to lead to reversing the substitution of natural gas for refined oil.

Table 4. Spatial spillover effects of environmental regulation for high regulation-high gas consumption intensity $(\mathrm{HH})$ and low regulation-low gas consumption intensity (LL) regions.

\begin{tabular}{|c|c|c|c|c|}
\hline \multirow{2}{*}{ Variable (ln) } & \multicolumn{2}{|c|}{$\mathbf{H H}$} & \multicolumn{2}{|c|}{ LL } \\
\hline & (1) & (2) & (3) & (4) \\
\hline$E R$ & $-0.0761^{* *}$ & $-0.1201^{* *}$ & 0.0283 & $0.0932 *$ \\
\hline$E R^{*} E C S$ & & 0.0620 & & $-0.4975^{* * *}$ \\
\hline$E R^{*} \operatorname{In} d^{*} E C S$ & & $0.9282 * *$ & & $-3.9289^{* * *}$ \\
\hline ER $^{*}$ OilPrice ${ }^{*}$ ECS & & 2.4076 & & $-11.4932 *$ \\
\hline Ind $^{*} E C S$ & $0.6139 * *$ & 0.2528 & $-2.2068^{* *}$ & $-3.8447^{* * *}$ \\
\hline GDP & $0.5209^{* * *}$ & $0.5276^{* * *}$ & $1.1624^{* * *}$ & $1.2397^{* * *}$ \\
\hline GasPop & $0.3807^{* * *}$ & $0.4143^{* * *}$ & $0.4373^{* * *}$ & $0.5644^{* * *}$ \\
\hline Ind & 0.0276 & 0.1797 & 0.3191 & 0.0427 \\
\hline ECS & $-0.1784 *$ & $-0.1851 *$ & $-0.4574^{* * *}$ & -0.0908 \\
\hline OilPrice & 0.5832 & 0.3044 & 0.7740 & 2.1249 \\
\hline GasPrice & -0.3645 & $-0.4432^{* *}$ & $-1.2042^{* * *}$ & $-1.2811^{* * *}$ \\
\hline PipelineLen & $0.2674^{* * *}$ & $0.2658^{* * *}$ & $0.2291 * *$ & 0.1077 \\
\hline$W^{*} E R$ & -0.0097 & 0.0098 & -0.0494 & 0.1911 * \\
\hline$W^{*} E R^{*} E C R$ & & $-0.4738^{* *}$ & & -0.3918 \\
\hline$W^{*} E R^{*} \operatorname{Ind}{ }^{*} E C S$ & & $-2.2117^{* * *}$ & & -2.1756 \\
\hline$W^{*} E R^{*}$ OilPrice $^{*} E C S$ & & $-25.163^{* * *}$ & & 13.8235 \\
\hline$W^{*} Y$ & 0.0811 * & 0.0851 * & $0.1838^{* * *}$ & $0.1888^{* * *}$ \\
\hline Rbar $^{2}$ & 0.7766 & 0.8040 & 0.8905 & 0.9057 \\
\hline
\end{tabular}




\section{Discussion}

\subsection{Analysis of Results based on the Current Situation of China's Environmental Policy}

In the previous sections, we analyzed the internal mechanism of the impact of China's environmental regulation policies on natural gas consumption. To further understand the practical effects of these paths, we selected several major environmental governance measures in China, combined with the mechanism framework and empirical analysis results we have constructed, to reveal the impact mode and effect of China's environmental regulation policies on natural gas consumption, to evaluate whether these specific measures can effectively promote the growth of natural gas consumption, and to analyze what are the main obstacles to implementing these policies.

There are many kinds of environmental regulation tools, and the choice of environmental regulation tools is closely related to governance objects and objectives $[35,36]$. In China, environmental regulation policies that are strongly related to natural gas consumption include mainly air pollution prevention and control policies and high pollution energy restraint policies. We selected several specific measures that are strongly enforced, that occupy a dominant position in environmental governance, and that have received extensive attention. These measures include levying a sewage tax (fee), increasing the levy of a refined oil consumption tax, enterprise environmental protection subsidies and total coal consumption control policies. We will analyze the potential impact of these four measures on natural gas consumption based on the calculation results.

The government levies a pollution tax (fee) on polluting enterprises to force them to change their production methods and adopt cleaner energy and production technologies. However, this kind of replacement often requires relatively high costs. Therefore, many Chinese industrial enterprises often follow the pollution control mode of "pollution first, treatment later" and use environmental protection investment to treat pollutants. It is difficult to achieve the cleanness of energy inputs [37]. In Table 1, the coefficient $\ln \left(E R^{*} I n d^{*} E C S\right)$ in Model $V$ is significantly negative, thus not only confirming the above conclusion but also showing that this "pollution first, treatment later" environmental treatment will also significantly negatively affect natural gas consumption. This negative effect on natural gas consumption is because levying sewage taxes focuses only on the results and does not control the generation of pollutants from the input of energy production. Therefore, a variety of environmental regulation policies are needed to act on all links of the industrial chain and jointly promote cleaner production activities.

In addition, China's sewage tax collection and environmental protection subsidies are implemented by the environmental protection department; these measures target most of China's industrial enterprises, thereby raising the question of whether the "sewage tax (fee)-environmental protection subsidies" can be effectively transformed [38]. This issue is controversial and has not been discussed by scholars. We have not included the evaluation index of the conversion efficiency of this process in the empirical research of this article, but the current results show that the effect of this conversion mechanism is very unsatisfactory. Finding the balance point of the "reward-punishment" mechanism of China's environmental protection department for polluting enterprises and achieving the maximization of pollution control efficiency will be one of our future research directions.

Unlike the "pollution first, treatment later" mode of the sewage tax, the coal total amount control policy and the refined oil consumption tax are designed to control pollutants at the source. Liu et al. (2019)'s research shows that the coal total amount control policy can effectively restrict coal consumption and promote the transformation of the energy consumption structure [39]. We obtained the same result from the perspective of natural gas consumption. The coefficient $\ln \left(E R^{*} E C S\right)$ in Model IV is significantly positive (Table 1), thus showing that restricting coal consumption can indeed promote the increase of natural gas consumption and the clean development of the energy consumption structure. In Table 3, the coefficient $\ln \left(\mathrm{W}^{*} \mathrm{ER}{ }^{*} \mathrm{ECS}\right)$ in Model VIII is also significantly positive, thus further illustrating that controlling coal consumption can produce positive spatial overflow on natural gas consumption in surrounding areas and form a diffusion effect. 
Compared with the total coal control policy, the environmental regulation measures to increase the consumption tax on highly polluting energy is more market oriented. Research by Parry et al. (2014) shows that the adjustment of the refined oil consumption tax can effectively reduce the negative externalities of the environment caused by excessive consumption [40]. In Table 1, the coefficient $\ln \left(\mathrm{W}^{*} E R^{*} \mathrm{ECS}\right)$ in ModelVis insignificantly positive, thus showing that China's environmental control measures to adjust the price of refined oil can potentially promote the consumption of natural gas, but this potential positive effect has not yet occurred significantly. We believe that further increasing the consumption tax on refined oil is an effective measure to accelerate the substitution of natural gas for refined oil in the energy terminal consumption market.

More importantly, the objective reality of China's environmental governance is that the above four measures exist simultaneously and are interrelated [41]. Model VII of Table 1 and Model XII of Table 3 both reflect the response of natural gas consumption when multiple environmental governance paths coexist. In Model VII, only the coefficient $\ln \left(E R^{*} I^{*}{ }^{*} E C S\right)$ is significant and positive; the coefficient $\ln \left(E^{*}\right.$ OilPrice*ECS), especially, is negative (as is the case in Model VI). These results indicate that the regulation of the oil industry will weaken the direct effect of ER on the energy consumption structure and will even create the inverse substitution effect of natural gas on refined oil in the energy market. In Model XII, the spillover efficiency from $\ln (E R)^{*} \ln (\operatorname{Ind})^{*} \ln (\mathrm{ECS})$ will be important in hindering the overall increase of natural gas consumption in neighboring provinces while weakening the spatial effects from the other terms. The above conclusion shows that there are contradictions and conflicts among various environmental governance paths in China, and these contradictions and conflicts have weakened the influence of these paths on natural gas consumption. As the main object of environmental regulation, industrial enterprises correspond to path 2 , which has an inhibitory effect on natural gas consumption and occupies a leading position. Therefore, China needs to strengthen the construction of market-driven environmental regulations, strengthen the restriction on traditional high-pollution energy consumption and guide industrial enterprises to prefer clean energy such as natural gas from the choice of raw materials.

\subsection{Important Factors Leading to Regional Differences in Environmental Regulation Effect}

Furthermore, the energy consumption and industrial energy consumption structures of the provinces in the $\mathrm{HH}$ and LL regions are observed to exploit the difference in the effects of environmental regulation policies on natural gas consumption between these two regions, as shown in Figure 6.

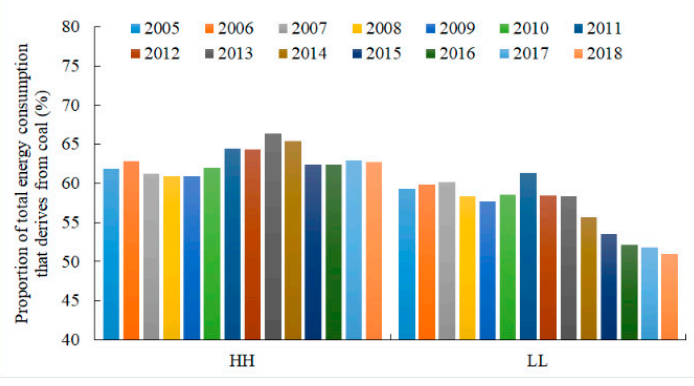

a. Energy consumption structure

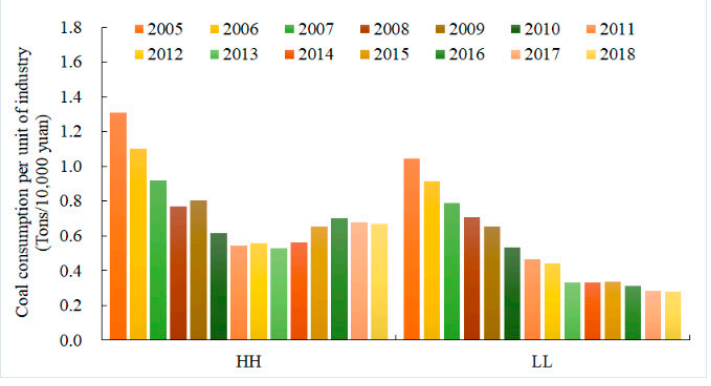

b. Industrial energy consumption

Figure 6. $\mathrm{HH}$ area and LL area: industrial structure, energy consumption structure and industrial energy consumption characteristics.

The $\mathrm{HH}$ area includes provinces mainly in northeast and northwest China, such as Xinjiang, Gansu, Inner Mongolia, Shanxi, Shaanxi, Hebei and Heilongjiang, where heavy industry accounts for relatively much of the land area. Therefore, the energy consumption structure dominated by coal consumption in these areas has not changed significantly, as indicated by the change in the proportion of total energy consumption that derives from coal in this area (see Figure 6a). Additionally, Figure 6b 
shows, first, a downward trend in industrial coal consumption and then an upward trend, thereby indicating that environmental regulation will displace industrial energy consumption in this area. Compared with the HH region, the LL region comprises mainly central, eastern and southern China, such as Shaanxi, Hubei, Hunan, Jiangxi, Jiangsu, Zhejiang, Shanghai, Fujian and Guangdong. The coal consumption in this region shows a downward trend, while the intensity of industrial coal consumption has also decreased significantly, thus showing that competing to reduce the intensity of environmental regulation from the local governments is beneficial in promoting a cleaner transformation of the regional energy consumption structure.

\subsection{Universality of Research Framework and Model}

In this part, we briefly discussed whether our research framework and models can be applied to other countries, such as some multi-party countries. We believe that our research ideas are applicable in these countries, but the models and variables need to be adjusted according to the national conditions of specific countries. Our model can be applied to measure the path of environmental regulation affecting natural gas consumption in other countries with different systems mentioned. However, the setting of the exogenous impact of environmental regulation competition cannot be applied to other countries. China's decentralization system is "Top to Bottom", resulting in competition to increase or reduce environmental regulation. However, in the so-called "Bottom to Top" non-socialist countries, voters can eliminate governments that do not actively protect the environment through the mechanism of "Voting with Feet" [28]. Governments in such countries are more inclined to improve the intensity of environmental regulation, which is different from China. When our model is applied to these countries, the exogenous condition of environmental regulation competition needs to be changed.

\section{Conclusions and Policy Implications}

The nonspatial panel model and spatial Dubin model are introduced in this paper to deeply study the impact mechanism of environmental regulation in China on natural gas consumption and identify the conduction paths of the spatial spillover effect of environmental regulation. The following conclusions and policy implications can be drawn from the research:

Environmental regulation does not significantly directly affect local natural gas consumption, but there is a $\mathrm{N}$-inverted curve between the two at the national level in China. In the context of the central government's environmental assessment, local governments have been constantly adjusting the intensity of environmental regulation to increase natural gas consumption, but these governments have to face a trade-off between improving environmental quality and economic development. It is particularly important for local governments to make the policies of environmental regulation suitable for economic activities and production patterns that promote the consumption of natural gas.

Generally, there are mainly three conduction paths by which environmental regulation affects natural gas consumption: The first path is to directly restrict high-pollution coal consumption in the mix energies, thus indirectly promoting natural gas consumption. The second path is to levy a pollution discharge tax on industrial enterprises as an environmental protection subsidy to achieve low carbonization of industrial energy consumption and to inhibit overall natural gas consumption in the region. The third path is to levy a consumption tax on refined oil and convert the tax into a clean energy subsidy via transfer payment, thereby benefiting the substitution of natural gas for refined oil in commercial and residual consumption. However, if local governments formulate environmental policies based on these three mechanisms and implement them together, conflicts of interest among the government, enterprises and market agents will result, thus weakening the effect of environmental governance. Currently, to improve the consumption of natural gas and environmental quality, it is still necessary to give priority to the policy of controlling the total amount of coal to maximize the positive role of environmental regulation.

In the context of environmental assessment for the local governments, local government usually competes for natural gas in environmental regulation tournaments. Therefore, the spillover effects 
from regulation on the energy consumption structure and the refined-oil price will improve the overall national gas consumption to accelerate the integration of the natural gas market, but the effects of industrial coal consumption will displace gas consumption, thereby resulting in increased dependence of the industry on coal. Thus, two environmental policies regulating total coal consumption and a refined oil consumption tax-clean energy subsidy should be adopted by central and local governments to increase natural gas consumption in the natural gas market.

In the formulation and selection of environmental policies, regional differences among local governments should be considered to promote natural gas consumption to balance the trade-off between environmental quality improvement and economic development. The provinces with $\mathrm{HH}$ regulation intensity in northeast and northwest China increasingly depend on coal consumption in their energy mix. Therefore, the policy of sewage charges (taxes)-environmental subsidy should be adopted and implemented by the governments in this $\mathrm{HH}$ region to drive the growth of natural gas consumption. This will trigger competition, which will be better for promoting the economic and social development of this region with low carbonization. On the contrary, the provinces with LL regulation intensity in central, eastern and southern China should have gradually reduced the dependence on coal consumption. Therefore, the intensity of environmental regulation in this region should be reduced to better use the market price mechanism to promote the competition in the natural gas market in this region, thus promoting the low carbonization of the energy consumption structure and the growth of natural gas consumption in this region.

Author Contributions: X.W., X.L., N.Z., J.X. and J.C. conceptualized the idea of the study design; X.W. and X.L. performed statistical analysis and wrote the manuscript; X.W., X.L., N.Z. revised the article; X.W., N.Z., J.X. and J.C. provided fund support. Runfeng Tian, Zhankun Liu and Yangyang Qiu helped in the data collection and provided their intellectual insights. All authors have read and agreed to the published version of the manuscript.

Funding: This research was funded by the National Natural Science Foundation of China (Nos. 71874166, 71991482, and 71673257), China Scholarship Council (No. 201906410051), and the Open Fund Project from Laboratory of Carrying Capacity Assessment for Resource and Environment, Ministry of Natural Resources of China (No. 1911000000033).

Acknowledgments: We are grateful for the coauthors, comments and suggestions from the editor and anonymous reviewers who helped improve the paper. We would also like to express our gratitude to the China National Natural Science Foundation for providing funding support.

Conflicts of Interest: The authors declare no conflict of interest.

\section{References}

1. Percival, R.V.; Schroeder, C.H.; Miller, A.S.; Leape, J.P. Environmental Regulation: Law, Science, and Policy; Wolters Kluwer Law \& Business: New York, NY, USA, 2017.

2. Erickson, P.; Lazarus, M. Would constraining US fossil fuel production affect global $\mathrm{CO}_{2}$ emissions? A case study of US leasing policy. Clim. Chang. 2018, 150, 29-42. [CrossRef]

3. $\mathrm{Xu}, \mathrm{B}$; Lin, B. Can expanding natural gas consumption reduce China's $\mathrm{CO}_{2}$ emissions? Energy Econ. 2019, 81, 393-407. [CrossRef]

4. Ogden, J.; Jaffe, A.M.; Scheitrum, D.; McDonald, Z.; Miller, M. Natural gas as a bridge to hydrogen transportation fuel: Insights from the literature. Energy Policy 2018, 115, 317-329. [CrossRef]

5. Gillessen, B.; Heinrichs, H.; Hakea, F.; Allelein, H.-J. Natural gas as a bridge to sustainability: Infrastructure expansion regarding energy security and system transition. Appl. Energy 2019, 251, 113377. [CrossRef]

6. Lin, B.; Li, J. Transformation of China's Energy Structure under the Constraints of Environmental Governance-Analysis Based on Coal and Carbon Dioxide Peaks. Chin. Soc. Sci. 2015, 9, 84-107.

7. BP. Statistical Review of World Energy; BP: London, UK, 2019.

8. IEA. Gas Market Liberalisation Reform. 2019. Available online: https://webstore.iea.org/gas-marketliberalisation-reform (accessed on 16 May 2019).

9. Liu, H. "Coal to Gas" Project is Prudent and Prudent: Based on Investigation and Analysis of Beijing "Coal to Gas" Project. Macroecon. Res. 2015, 04, 9-13. 
10. Shi, D.; Li, S. Research on the Effect of Beijing-Tianjin-Hebei Green Coordinated Development-A Quasi-natural Experiment Based on the Implementation of the "Coal to Gas, Electricity" Policy. Econ. Manag. Res. 2018, 39, 65-78.

11. Zhou, S.; Sun, Y.; Wang, J.; Guo, H.; Zhang, M.; Liang, Y. On non-discriminatory third-party access and regulation of provincial level natural gas pipeline network facilities: A case study of Shaanxi Province. Nat. Gas Ind. 2017, 37, 107-114.

12. Lin, X. Price supervision, government profit-seeking, and natural gas system reform: An analysis of cases from Fujian Province. Nat. Gas Technol. Econ. 2017, 11, 63-68.

13. Chai, J.; Liang, T.; Lai, K.K.; Zhang, Z.G.; Wang, S. The future natural gas consumption in China: Based on the LMDI-STIRPAT-PLSR framework and scenario analysis. Energy Policy 2018, 119, 215-225. [CrossRef]

14. Wang, T.; Lin, B. China's natural gas consumption and subsidies-From a sector perspective. Energy Policy 2014, 65, 541-551. [CrossRef]

15. Zhang, Y.; Ji, Q.; Fan, Y. The price and income elasticity of China's natural gas demand: A multi-sectoral perspective. Energy Policy 2018, 113, 332-341. [CrossRef]

16. Li, L.; Xu, T.; Li, F.; Jiao, J. Gravity Center Evolution Paths and Growth Factor Decomposition of Residential Natural Gas Consumption in China. J. Nat. Resour. 2017, 32, 606-619.

17. Cheng, J.; Liu, L.; Wang, X.; Xiao, J. Analysis of the elasticity of market demand elasticity in natural gas regions and the impact of price regulation. China Popul. Resour. Environ. 2014, 24, 131-140.

18. Lin, B.; Liu, C. China's Energy Subsidy Reform and Effective Energy Subsidies. Chin. Soc. Sci. 2016, 10, 52-71.

19. Liu, C.; Lin, B. Analysis of the changes in the scale of natural gas subsidy in China and its decomposition factors. Energy Econ. 2018, 70, 37-44. [CrossRef]

20. Smil, V. Energy Transitions: History, Requirements, Prospects; ABC-CLIO: Santa Barbara, CA, USA, 2010.

21. Dong, K.; Sun, R.; Dong, C.; Li, H.; Zeng, X.; Ni, G. Environmental Kuznets curve for PM2. 5 emissions in Beijing, China: What role can natural gas consumption play? Ecol. Indic. 2018, 93, 591-601. [CrossRef]

22. Cesur, R.; Tekin, E.; Ulker, A. Air pollution and infant mortality: Evidence from the expansion of natural gas infrastructure. Econ. J. 2016, 127, 330-362. [CrossRef]

23. Zhou, X.; Feng, C. The impact of environmental regulation on fossil energy consumption in China: Direct and indirect effects. J. Clean. Prod. 2017, 142, 3174-3183. [CrossRef]

24. Tang, Y.; Liang, R. Whether the energy substitution policy can improve air quality and the impact of energy pricing mechanism. China Popul. Resour. Environ. 2018, 28, 83-95.

25. Zhang, K.; Zhang, Z.Y.; Liang, Q.M. An empirical analysis of the green paradox in China: From the perspective of fiscal decentralization. Energy Policy 2017, 103, 203-211. [CrossRef]

26. Zhu, P.; Zhang, Z.; Jiang, G. FDI and Environmental Regulation: An Empirical Study from the Perspective of Decentralization. Econ. Res. 2011, 46, 133-145.

27. Zhu, X.; He, C.; Li, Q.; Mao, X. Local Government Competition, Environmental Regulation and Urban Air Pollution in China. China Popul. Resour. Environ. 2018, 28, 103-110.

28. Zhang, W.; Zhang, L.; Zhang, K. Inter-provincial competition model and its evolution in the intensity of environmental regulation in China: An analysis based on the Durbin fixed-effect modell of two-zone space. Manag. World 2010, 12, 34-44.

29. Shao, S.; Li, X.; Cao, J.; Yang, L. Economic Policy Choices for Haze Pollution Control in China: A Perspective Based on Space Spillover Effects. Econ. Res. 2016, 9, 73-88.

30. LeSage, J.; Pace, R.K. Introduction to Spatial Econometrics; Chapman and Hall/CRC: Boca Raton, FL, USA, 2009.

31. Elhorst, J.P. Spatial Econometrics: From Cross-Sectional Data to Spatial Panels; Springer: Berlin/Heidelberg, Germany, 2014.

32. Sun, W.; Yang, Q. Measurement of environmental regulation intensity: Methods and advances. Eco-Economy 2017, 33, 132-138.

33. Anselin, L. Local indicators of spatial association-LISA. Geogr. Anal. 1995, 27, 93-115. [CrossRef]

34. Raiher, A.P.; Stege, A.L.; Sander, S.D.C.A. Effect of Exports on the Economic Growth of Brazilian Microregions: An Analysis with Geographically Weighted Regression. Int. J. Econ. Financ. 2017, 9, 236-248. [CrossRef]

35. Peng, J.; Xiao, J.; Zhang, L.; Wang, T. The impact of China's 'Atmosphere Ten Articles' policy on total factor productivity of energy exploitation: Empirical evidence using synthetic control methods. Resour. Policy 2020, 65, 101544. [CrossRef] 
36. Lee, J.H.; Lim, S. The selection of compact city policy instruments and their effects on energy consumption and greenhouse gas emissions in the transportation sector: The case of South Korea. Sustain. Cities Soc. 2018, 37, 116-124. [CrossRef]

37. Yuan, Y.; Geng, D. Transmission Mechanism of Environmental Policy and Development of China's Environmental Protection Industry-A Game Study Based on Government, Sewage Disposal Enterprises and Environmental Protection Enterprises. Chinas Ind. Econ. 2010, 67-76.

38. De Cara, S.; Henry, L.; Jayet, P.A. Optimal coverage of an emission tax in the presence of monitoring, reporting, and verification costs. J. Environ. Econ. Manag. 2018, 89, 71-93. [CrossRef]

39. Liu, B.; Sun, Z.; Sun, H. Path and Optimization Strategy of Energy Space Allocation under the Control of Total Consumption. China Popul. Resour. Environ. 2019, 29, 96-106.

40. Parry, I.; Heine, D.; Li, S.; Lis, E. How Should Different Countries Tax Fuels to Correct Environmental Externalities? Econ. Energy Environ. Policy 2014, 3. [CrossRef]

41. Ren, S.; Li, X.; Yuan, B.; Chen, X. The effects of three types of environmental regulation on eco-efficiency: A cross-region analysis in China. J. Clean. Prod. 2018, 173, 245-255. [CrossRef]

(C) 2020 by the authors. Licensee MDPI, Basel, Switzerland. This article is an open access article distributed under the terms and conditions of the Creative Commons Attribution (CC BY) license (http://creativecommons.org/licenses/by/4.0/). 